\title{
Social Media in Libraries: It's like, Complicated.
}

\author{
Nick Canty, University College London
}

\begin{abstract}
This article considers how some major libraries across the world are using social media platforms. Libraries have engaged with the 'household brands' familiar to us all regardless of geographic location or language although their use of the platforms varies widely.

Although there are no surprises in how the platforms are used and what content is made available by each library, the overall impression is of patchy use of the platforms, with some libraries fully embracing all platforms while others concentrating on fewer. A key message is that high quality images for websites seems to succeed in engaging with people.

The article is based around social media data collected from library accounts on Facebook, Twitter, YouTube and Blogs between July and August 2012, extended for three months for YouTube due to the lack of regularly submitted content. After a discussion about the role of social media in libraries the data is analysed for each platform.
\end{abstract}

Keywords: Social media, libraries, online engagement, Library 2.0, Facebook, YouTube, Twitter, Blogs

\section{Introduction}

The growth of social media and social networking sites has been one of the most impressive aspects of the internet in recent years and its popularity is undeniable. Twenty two percent of all time spent online is spent on social media sites, or one in every four and a half minutes and three quarters of global consumers who go online visit social media sites ${ }^{1}$. Whether or not we agree with the view that social media have the ability to break down the traditional barriers between the public and the private by putting power in the hands of the user or take a more sceptical view that social media is little more than a 'daily me' ${ }^{2}$ or 'mass self communication, ${ }^{3}$, it is safe to assume that social media is here to stay and is now a priority for many organizations. The challenge for all organizations, but particularly acute for people working in the information industry, is how to harness and exploit these communication channels to best effect. The disputed and subjective term Library 2.0 is open to interpretation but what is clear is that in a networked society library service is likely to be increasingly virtual, participatory and collaborative with the focus on user centered change and participation. In this scenario, also termed radical trust, the library becomes user generated ${ }^{4}$. Engaging with social media is a step towards this scenario.

This article examines how social media tools are being used by some major libraries across the world. The article is based on data analysis of library use of social media sites and provides some insight into how libraries are engaging with social media. Libraries are

\footnotetext{
${ }^{1}$ http://blog.nielsen.com/nielsenwire/global/social-media-accounts-for-22-percent-of-time-online/

${ }^{2}$ Sunstein. 2007 in Misunderstanding the Internet. Routledge. 2012. Oxon.

${ }^{3}$ Castells 2009. Communication Power. Cambridge University Press. Cambs.

${ }^{4}$ Berube. 2011. Do You Web 2.0? Public Libraries and Social Networking pp30. Chandos Publishing. Cambs.
} 
accustomed to technological change and many seem to have embraced social media with enthusiasm. Much of the discussion around social media use in libraries has appeared in practitioner publications rather than academic journals, a notable issue which suggests the debate is still in the stage of direct knowledge transfer rather than analysis.

\section{Social Media and Social Networks: Definitions and Descriptions}

The networked society is today a reality with billions of people connected to the internet and able to communicate through social media such as Twitter and Facebook. However, although the terms social media, social networks and Web 2.0 have become ubiquitous it is worth dissecting these terms to provide some clarity in this complex world. Drawing a line between the related concepts of Web 2.0 and User Generated Content we could define social media as 'a group of Internet-integrated applications that build on the ideological and technological foundations of Web 2.0 (the platform) and that allow the creation and exchange of User Generated Content (the ways in which people make use of social media) ${ }^{5}$.

There are no agreed definitions of the umbrella term 'social media' but the table below provides a useful framework.

\footnotetext{
${ }^{5}$ Kaplan, Haenlein (2010). Users of the world, unite! The challenges and opportunities of Social Media. P 61. Business Horizons (2010) 53, 59-68.
} 


\section{Collaborative projects}

These allow the joint creation and sharing of content between users with the underlying philosophy that the effort of many leads to better outputs. The leading example here is Wikipedia.

Blogs

Blogs can trace their history back to the earliest days of the Internet but they took off around 1997-98. Today there are estimated to be more more than 160 million blogs in existence, either active or abandoned in cyberspace.

\section{Content communities}

The sharing of content across different media types such as videos on YouTube, photos on Flickr and PowerPoint on Slideshare.

\section{Social networking sites}

These are applications in which a social network's members serve dual roles as both the suppliers and the consumers of content. Social networks allow users to connect with each other and exchange a wide variety of media content, be it film, photos, text or audio files among others. Increasingly used by corporations as a marketplace to sell goods.

\section{Virtual social worlds}

In virtual worlds users choose their behaviour and live as an avatar in a three dimensional environment. The most prominent virtual world is Second Life.

\section{Virtual game worlds}

These game worlds allow users to appear as personal avatars and interact with others in in two virtual worlds; games and social worlds. Games require users to follow a set of rules in the context of massively multiplayer online roleplaying games (MMORPG). Examples here are Microsoft's X Box and Sony's PlayStation. Users adopt a persona and interact with other players across the world.

Six types of social media. Kaplan, Haenlein 2010

\section{Why use social media in the library?}

Social media can be powerful information dissemination tools and offer a way for libraries to promote their activities, resources and services while allowing a two way dialogue with stakeholders . A 2010 survey by the Society of Chief Librarians in the UK ${ }^{6}$ found that internet users trust library staff more than most other providers of online support and information, and public library staff are second only to doctors in terms of the trust placed in them by seekers of information. The core of the work of librarians is the sharing information so this would suggest librarians are in a unique position to implement and exploit social media to their (and their users) advantage.

Social media can be used in a variety of communication methods broadly summarized as broadcast messages, response to enquiries and then conversation between institution and

\footnotetext{
${ }^{6}$ http://www.goscl.com/survey-reveals-librarians-second-only-to-doctors-in-publics-trust/
} 
users but regardless of the approach taken there are compelling reasons for libraries to engage with social media. Social media can give a competitive edge in a time of major technological change and with access to information widely available libraries need to demonstrate the value of their proposition. Social media give librarians a way to reach out to their users who may not have considered the library as a resource for their information needs.

\section{Cost and ease of use}

Setting up accounts and getting started is easy and free. Patrons use the same tools in their social and work life so social media fit in with the workflow and expectations of many users. However, judging what success looks like in social media is notoriously difficult as unlike in conventional direct marketing where there are recognised response rates (a 1\% return rate in direct marketing is a commonly agreed industry norm), it is much harder to measure something intangible like social media. Although there are the easy measures such as the number of Twitter followers, Facebook likes and comments, measuring 'engagement' or customer satisfaction is much more problematic. In addition a myth has arisen that suggests that social media is completely 'free' when very real costs, particularly staff time, are attached.

Good social media engagement requires considerable staff time and management commitment to ensure the reputation of the library is enhanced in the eyes of users.

\section{Communication with patrons}

Social media offers an accessible way to engage with patrons and potential patrons, particularly the elusive younger generation or 'digital natives' who are now entering the workplace having grown up in a culture of sharing information, inviting others to contribute and contributing to online discussions. It is a myth that young people are driving social technologies and but they nevertheless are heavily active online and tend to see a clear division between work/study and leisure activities and libraries have a specific function in the work/study sphere.

The two-way communication that now exists between library and user can be helpful for responding to user collection requests.

\section{Marketing and promotion}

For many organisations social media tools are used primarily as part of their marketing and promotion activities. For libraries this enables them to communicate additions to collections, promote exhibitions, talks and so on. It is worth remembering however that although social media may provide the tools, the library still has to provide the content to promote and that takes time and money. Social media can only promote what is feed into it.

\section{A way to improve customer service}

With so much focus on social media for marketing and broadcasting we overlook the participatory nature of social media. Social media are frequently seen as tools for marketing 
and promotion but they also offer the chance to improve customer service issues and complaints. Social media allow an organization to monitor what's being said about them and respond to positive (and particularly negative) feedback quickly. There are now numerous platforms which offer these services although libraries need to consider who is responsible for this activity and how much time to devote to this as this hidden cost and rise.

This participatory communication method allows users to connect with knowledge curators and trust to be built between the two parties.

\section{Methodology}

To gain an insight into the social media use by libraries data was collected from the social media sites used by six major libraries across the world; the British Library, the Library of Congress, Biblioteca Nacional de Espana, Bibliotheque National de France, the National Library of Australia, and the National Library of Scotland. All the libraries use the familiar 'household brands' we are familiar with despite their native languages and geographical differences.

All the libraries have adopted a multichannel approach although each platform has particular strengths and is appropriate for different uses. A framework to consider the appropriateness of different channels was compiled by the British Informatics Society. Twitter is particularly good for rapidly changing information and for connecting with communities whereas YouTube is appropriate for demonstrating products. Corporate blogs may be considered for general information sharing. ${ }^{7}$ Getting the tome right for any channel is a major consideration.

\begin{tabular}{|l|c|c|c|c|c|}
\hline Library & Twitter & Facebook & YouTube & Blogs & Other \\
\hline British Library & $\mathrm{X}$ & $\mathrm{X}$ & $\mathrm{X}$ & $\mathrm{X}$ & $\mathrm{RSS}$ \\
\hline Library of Congress & $\mathrm{X}$ & $\mathrm{X}$ & $\mathrm{X}$ & $\mathrm{X}$ & Flickr \\
\hline $\begin{array}{l}\text { Biblioteca Nacional de } \\
\text { Espana }\end{array}$ & $\mathrm{X}$ & $\mathrm{X}$ & $\mathrm{X}$ & & Flickr \\
\hline $\begin{array}{l}\text { Biblioteque National de } \\
\text { France }\end{array}$ & $\mathrm{X}$ & $\mathrm{X}$ & $\mathrm{X}$ & $\mathrm{X}$ & No \\
\hline $\begin{array}{l}\text { National Library of } \\
\text { Australia }\end{array}$ & $\mathrm{X}$ & $\mathrm{X}$ & $\mathrm{X}$ & $\mathrm{X}$ & Flickr \\
\hline $\begin{array}{l}\text { National Library of } \\
\text { Scotland }\end{array}$ & $\mathrm{X}$ & $\mathrm{X}$ & $\mathrm{X}$ & $\mathrm{X}$ & Flickr \\
\hline
\end{tabular}

\footnotetext{
${ }^{7}$ Brown E. 2010. Working the Crowd. Social Media Marketing for Business. British Informatics Society Limited. Swindon.
} 
Data in the tables in this article was captured between 22 July 2012 and 22 August 2012, although for YouTube this was extended for three months as there was significantly less activity on this platform. Social media statistics are a crude way to measure issues like 'engagement' or message penetration but they nevertheless provide a perspective on library use of social media and in addition social media analytics are widely understood measures.

\section{Visibility of Social Media on Library Homepages}

Having social media buttons on the home page suggests an organization is active and seeking to engage with external stakeholders. Finding social media sites therefore was easy depending on whether the library had links on their home pages but embedding these links in every page as headers or footers increases exposure. None of the libraries had a social media dashboard that aggregated all social media activity on one page which is a useful way to display content from disparate networks for visitors, as we all confirming which are the official sites in case there may be fake accounts operating.

Some libraries however had dedicated pages describing their use of social media and if these were available they are recorded in the table below.

\begin{tabular}{|l|c|c|}
\hline Library & $\begin{array}{c}\text { Social media links } \\
\text { on home page }\end{array}$ & Social media explanatory page \\
\hline & & NO \\
\hline BL & YES & NO \\
\hline LOC & YES & NO \\
\hline BNE & YES & http://www.loc.gov/homepage/connect.html \\
\hline BNF & YES & http://www.nls.uk/about-us/social-networking \\
\hline NLA & YES & \\
\hline NLS & YES &
\end{tabular}

The Library of Congress has comprehensive guidance and advice about its use of social media and similarly the National Library of Scotland explains its social media presence with a helpful 'What others are saying' link to a list of recent mentions on Twitter and other platforms. The BNF provides similar links to its social media platforms in three languages.

\section{Facebook}

With close to 1 bn users across the world, Facebook is one of the most visited websites in the world ${ }^{8}$.

\footnotetext{
${ }^{8}$ Alexa. http://www.alexa.com/topsites
} 


\begin{tabular}{|l|c|c|}
\hline Country & $\begin{array}{c}\text { \% Reach of } \\
\text { Active } \\
\text { Users }\end{array}$ & $\begin{array}{c}\text { Time per } \\
\text { Person }\end{array}$ \\
\hline Italy & $66 \%$ & $07: 00: 21$ \\
\hline Australia & $63 \%$ & $07: 45: 28$ \\
\hline United States & $62 \%$ & $06: 43: 22$ \\
\hline United Kingdom & $62 \%$ & $06: 19: 59$ \\
\hline Spain & $57 \%$ & $04: 04: 53$ \\
\hline France & $57 \%$ & $04: 33: 05$ \\
\hline Switzerland & $45 \%$ & $04: 18: 47$ \\
\hline Germany & $27 \%$ & $03: 42: 50$ \\
\hline Brazil & $26 \%$ & $01: 46: 50$ \\
\hline Japan & $3 \%$ & $00: 31: 38$ \\
\hline
\end{tabular}

Facebook Reach and Usage by Country for April 2010. Time per person refers to the time spent on Facebook in that month. Source: The Nielsen Company

The table below shows keys statistics for Facebook activity for the sample libraries. Posts on the wall by others were not counted, only posts originating from the page owner.

\begin{tabular}{|c|c|c|c|c|c|c|c|c|c|c|}
\hline \multicolumn{11}{|c|}{ Facebook } \\
\hline Library & Total Likes & Date first pos & Main location & No of posts & Total Comments & Total Shares & $\begin{array}{c}\text { Total Likes } \\
\text { last MONTH }\end{array}$ & Average likes per post & Average share per post & tAverage comment per post \\
\hline LOC & 74,629 & $7 / 17 / 2009$ & Washington $\mathrm{DC}$ & 18 & 38 & 793 & 1698 & 94.3 & 44.1 & 2.1 \\
\hline BNE & 121,000 & $11 / 17 / 2008$ & Madrid & 23 & 283 & 4284 & 9052 & 393.6 & 186.3 & 12.3 \\
\hline BNF & 9,689 & $2 / 19 / 2010$ & Paris & 15 & 10 & 334 & 398 & 26.5 & 22.3 & 0.7 \\
\hline ANL & 3,504 & $07 / 08 / 2009$ & Canberra & 27 & 23 & 104 & 395 & 14.6 & 3.9 & 0.9 \\
\hline NLS & 4668 & $01 / 09 / 2008$ & Glasgow & 48 & 162 & 357 & 1064 & 22.2 & 7.4 & 3.4 \\
\hline
\end{tabular}

Facebook statistics. Figures for likes, shares and comments relate to the period

$$
22 \text { July } 2012 \text { - } 22 \text { August } 2012
$$

All libraries populate Facebook with rich content which mix news, promotion of library resources and information about current projects or exhibitions. The column 'Main location' refers to where most visitors to the Facebook pages are based. Not surprisingly the majority of visitors to the libraries' Facebook pages are local, coming from the capital city with the exception of the National Library of Scotland which although located in Edinburgh saw most visitors coming from Glasgow.

The exhibitions promoted are both live events such as the Writing Britain exhibition in the British Library or Gyenes: Master Photographer at the Biblioteca Nacional de Espana in Madrid, or virtual in the form of photo albums. All the libraries make use of the 'events' section although there are significant differences in how up to date content is here, with the British Library scoring high for including future events as well as past events while other 
libraries have not updated details here going back to 2010 thereby giving the impression of forgotten or neglected pages.

The Biblioteca Nacional de Espana posts tended to be albums with richer content than the other libraries and this may account for the very impressive 'likes' and 'shares' they enjoy from what is only an average number of posts from this library.

Facebook was used for competitions by several libraries. The National Library of Scotland was running a successful engagement campaign at the time of writing, inviting the public to 'Scotishify' famous film quotes as part of a exhibition on Scotland's relationship with cinema, with the best entries winning $£ 100$ in cinema tokens. There were over 2000 quotes submitted to the gallery indicating considerable success engaging with the public with this campaign.

The experience of the NLS and BNE perhaps demonstrate the importance of providing high quality and engaging content on Facebook. Both institutions post good images which people respond well too.

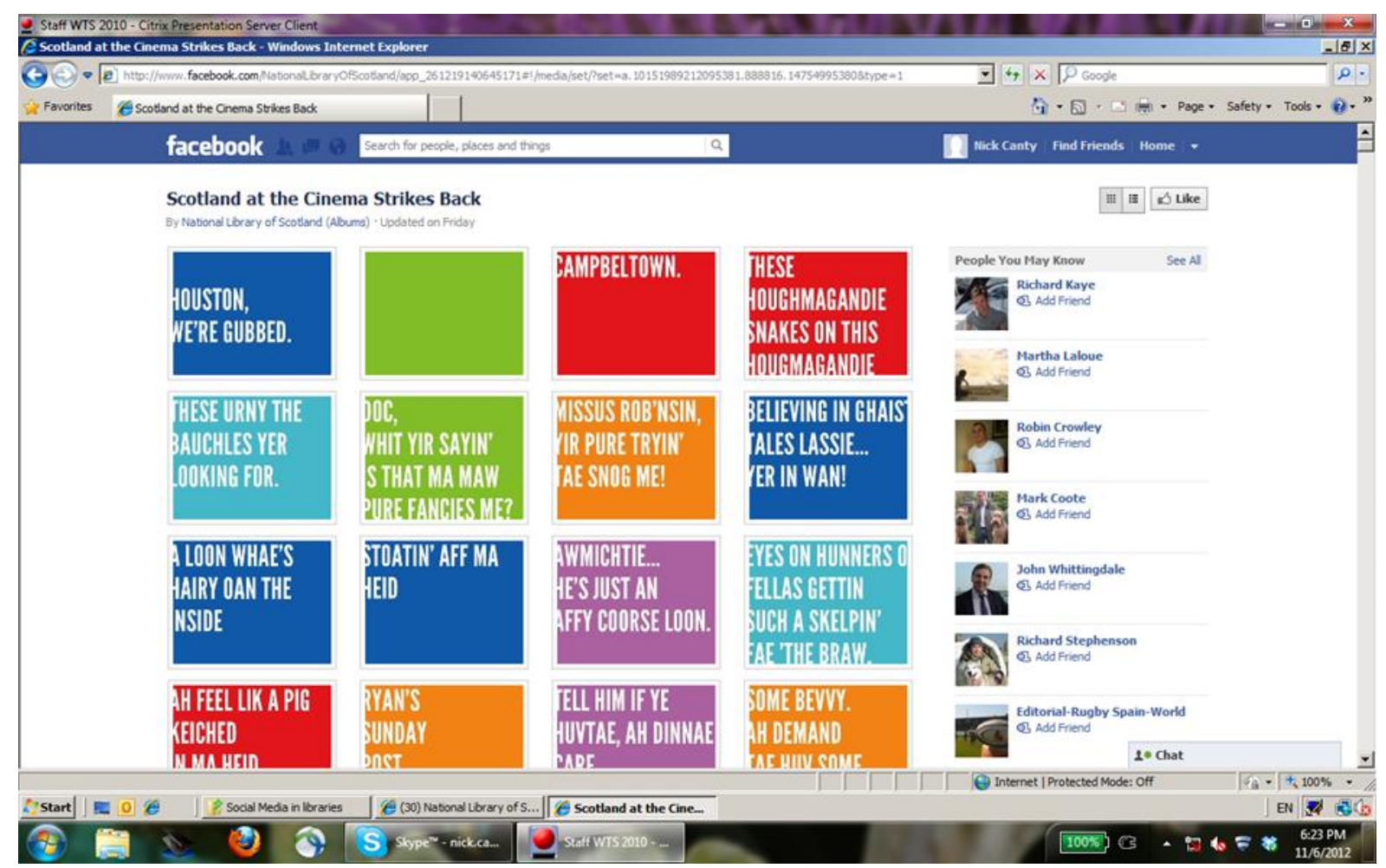

Scotland at the Cinema. National Library of Scotland Facebook page 2012

The other competition was the British Library's Race for Knowledge children's online game which gave children the chance to win an iPad as well as $£ 2$ off entry to the Writing Britain exhibition. Given this research was conducted during the 2012 Summer Olympics only two libraries made reference to the games; the National Library of Australia had a link to Fanny Durack's 1912 Olympic gold medal in the library's Treasure Explorer website, while the. The National Library of Australia gained its most 'likes' to posts relating to 'Cupcake day at the national library'. 
A feature of all the Facebook sites is that they present a corporate face to the world and there would seem to be little crossover between the corporate Facebook pages and the librarian's personal Facebook activity, a distinct difference from Twitter which often blurs the lines between personal and corporate.

\section{Twitter}

For many organisations Twitter has become their de facto social media presence and is their primary communications platform. Twitter perhaps better than other platforms exemplifies the ability to enable a rapid two way dialogue and library use of Twitter suggest this is a popular platform for reaching out to communities.

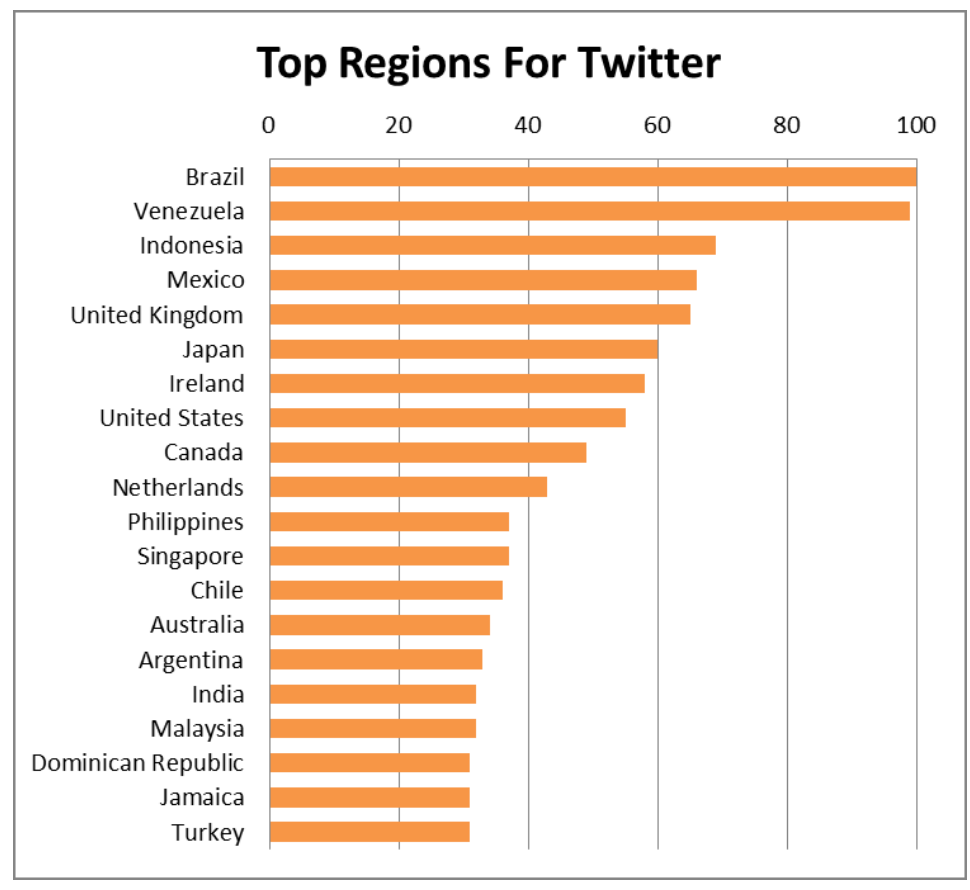

Source: Ignite Social Media 2012. Social Network Analysis Report

\begin{tabular}{|c|c|c|c|c|c|c|}
\hline Twitter & & & & & & \\
\hline Library & Account & First tweet & Followers & Follows & No of tweets & No of @mentions \\
\hline \multirow[t]{2}{*}{$\mathrm{BL}$} & twitter.com/britishlibrary & $2 / 24 / 2009$ & 316487 & 117 & 134 & 1,245 \\
\hline & $\begin{array}{l}\text { twitter.com/BIPC } \\
\text { twitter.com/Blpressoffice } \\
\text { twitter.com/BL_Shop } \\
\text { twitter.com/BL_Ref_Services }\end{array}$ & & $\begin{array}{c}4098 \\
1820 \\
1302 \\
939 \\
\end{array}$ & $\begin{array}{c}306 \\
1820 \\
440 \\
196 \\
\end{array}$ & $\begin{array}{c}53 \\
66 \\
61 \\
279 \\
\end{array}$ & - \\
\hline LOC & twitter.com/librarycongress & $1 / 27 / 2009$ & 416461 & 6 & 79 & 1,397 \\
\hline BNE & twitter.com/bne_biblioteca & $08 / 09 / 2011$ & 9680 & 57 & 142 & 340 \\
\hline \multirow[t]{2}{*}{ BNF } & twitter.com/GallicaBnF & & 8910 & 864 & 191 & 499 \\
\hline & twitter.com/LaboBnF & $4 / 23 / 2012$ & 2478 & 42 & 30 & 90 \\
\hline NLA & twitter.com/nlagovau & $09 / 02 / 2009$ & 7662 & 2776 & 168 & 429 \\
\hline NLS & twitter.com/natlibscot & $9 / 18 / 2009$ & 4520 & 495 & 98 & 257 \\
\hline
\end{tabular}


Twitter statistics. Figures for Follows, number of Tweets and number of @ mentions relate to the period 22 July 2012 - 22 August 2012. The data for Twitter was collected from TOPSY and TwitterCounter.

Libraries use Twitter for a various reasons, operational issues such as opening and closing times, or to showcase activities and new additions to collections and responding to questions and feedback. The way Twitter was used varied greatly across the libraries with some adopting a conversational approach while others tend to view Twitter as a conventional 'top down' broadcast medium. Twitter because of its fleeting nature lends itself well to a more light hearted and humorous tone which would be less appropriate for other sites such as Facebook or YouTube.

The British Library is the only library in the sample which has attempted to personalize the majority of its Twitter accounts by mentioning by name the individuals behind the account, presumably to give the impression that their Tweets are not merely news feeds from the PR office.

There is evidence of the libraries using Twitter to cross promote their activities for example by the BNE which was Tweeting about the final days of its Gyenes exhibition which was also heavily promoted on Facebook. This integrated approach to social media is vital to ensure engagement and the BNE's success here stands out.

There are imaginative ways of using Twitter with unconventional but engaging content, for example Orkney Libraries tweeted an entire book one Tweet a day supported by ongoing competitions, an innovative approach that won the library two GoldenTwit awards in 2011. The key to success with Twitter is striking the right level between being forced and over familiar and aloof and distanced from the audience.

\section{Blogs}

All the libraries in the sample have blogs but how the blogs were used varied widely across the institutions and with the exception of the BNE all the libraries have multiple blogs.

\begin{tabular}{|l|c|c|c|}
\hline Blogs & & & \\
\hline Library & No. of blogs & Total posts & $\begin{array}{c}\text { Total } \\
\text { comments }\end{array}$ \\
\hline BL & 17 & 52 & 0 \\
\hline LOC & 9 & 9 & 3 \\
\hline BNE & 1 & 4 & 9 \\
\hline BNF & 3 & 13 & 11 \\
\hline NLA & 5 & 7 & 2 \\
\hline NLS & 8 & 18 & 4 \\
\hline
\end{tabular}

Blog Statistics for 22 July 2012 - 22 August 2012. 
The tone taken in blogs varies from the formal to the informal with perhaps the most impressive activity undertaken by the Library of Congress. The library promotes its activities through its blogs but the librarians are given a free hand and the personal voice of the author gives imaginative access to the collections. A caveat confirms the blogs do not represent official Library of Congress communications. The NLA's blogs are well explained and give the chance to see behind the corporate body through blogs such as 'Page turners, what the National Library of Australia staff are reading' and 'Paddy's kitchen, a recipe blog to accompany the Patrick White exhibition' a good example of social media being used in conjunction with an event.

The long blog posts of the Bibliotheque National de France contains rich links to its catalogue records and external websites such as Wikipedia, making this blog a useful resource. Blog posts from the BNE tend to be long, essay style pieces supported by images from their collections.

It is worth noting that many of the blogs have commenting systems native to the platforms they were built on, if they integrated Facebook comments or other social media they would improve their chances of receiving more comments on their posts.

\section{YouTube}

Not surprisingly it is more difficult to post decent quality videos than static images and statistics for YouTube are varied.

\begin{tabular}{|c|c|c|c|c|c|c|}
\hline YouTube & & & & & & \\
\hline Library & $\begin{array}{l}\text { Number of } \\
\text { videos over } \\
3 \text { Months }\end{array}$ & $\begin{array}{c}\text { Number } \\
\text { of views } \\
\text { over } \\
3 \text { Months }\end{array}$ & First video & $\begin{array}{c}\text { Total } \\
\text { videos }\end{array}$ & $\begin{array}{c}\text { Total } \\
\text { views }\end{array}$ & Subscribers \\
\hline $\mathrm{BL}$ & 30 & 10420 & $10 / 29 / 2007$ & 36 & 111510 & 389 \\
\hline LOC & 33 & 6935 & $14 / 10 / 2008$ & 1,130 & $3,741,050$ & 13,019 \\
\hline $\mathrm{BNE}$ & 21 & 10629 & $20 / 04 / 2009$ & 129 & 327,451 & 928 \\
\hline $\mathrm{BNF}$ & 1 & 90 & $14 / 06 / 2011$ & 12 & 5024 & 77 \\
\hline NLA & 4 & 6166 & $17 / 12 / 2008$ & 29 & 179,131 & 82 \\
\hline NLS & 5 & 1374 & $30 / 11 / 2007$ & 42 & 310831 & 302 \\
\hline
\end{tabular}

The key indicator on YouTube is the number of subscribers as this shows how much people like the content and wish to maintain contact with the channel and suggests the library has built up a following instead of random viewers which indicates better engagement. This can be promoted with prompts and hints to urge people to subscribe to the channel. YouTube content ranges from interviews and recorded presentations of full conferences, such as the BNE's 'El libro como universo' to more practical issues about using the library such as 
searching online, taking out books or tracing family histories, an approach the NLA has taken with its YouTube offering.

The Library of Congress has a huge number of total views, almost 4 million but this could be explained by Google searches pointing to the videos rather than the marketing efforts of the library itself. For instance a Google search on 'Execution of Queen Mary' will bring up the LOC YouTube video fourth in the results list of LOC. The video has been viewed over 166,000 times.

\section{Other Social Media}

In addition to the platforms mentioned it is relevant to discuss other social media which are used by libraries. The photo sharing site Flickr is widely used by many libraries as it is a superb channel to display photographic collections. Flickr also allows for some imaginative use of tagging around adjectives (for example 'fear', 'hope') which allow for easy identification of relevant images. Re-use of images of Flickr can vary however and the wording on some Flickr accounts restricts commercial use whereas the Flickr images of the NLA are Creative Commons and allow unrestricted use, a strategy also deployed by the Library of Congress.

Pinterest (pinterest.com) is a relatively new social media platform which was founded in 2010. Pinterest acts like a virtual pinboard allowing users to organise and share images around themes, hobbies or activities such as crafts or even weddings. No libraries in the sample are using this platform at the time of writing although there are images of libraries posted to the site by members of the Pinterest.

\section{Conclusion}

In general libraries have adopted a multichannel approach to social media and are using the familiar household brands we use in our personal and professional lives. There are differences across the libraries and the libraries are using social media for many purposes, from marketing and promotion, opening up the resources of the library, and a customer service function by responding to queries and questions. It is impossible to know what social media success looks like for libraries without undertaking in-depth research but librarians are trusted information professionals are well placed to harness the opportunities available in the world of social media.

\section{Acknowledgments.}

The author would like to thank Sara Wingate Gray for her advice on this article.

\section{References}

Alexa. http://www.alexa.com/topsites

http://blog.nielsen.com/nielsenwire/global/social-media-accounts-for-22-percent-of-timeonline/ 
Sunstein. 2007 in Misunderstanding the Internet. Routledge. 2012. Oxon.

Castells 2009. Communication Power. CUP.

Berube. 2011. Do You Web 2.0? Public Libraries and Social Networking pp30. Chandos Publishing. Cambs.

Kaplan, Haenlein (2010). Users of the world, unite! The challenges and opportunities of Social Media. P 61. Business Horizons (2010) 53, 59-68.

http://www.goscl.com/survey-reveals-librarians-second-only-to-doctors-in-publics-trust/ Pavia and Kishtware 2009. Twitter is for old people

Brown E. 2010. Working the Crowd. Social Media Marketing for Business. British Informatics Society Limited. Swindon 